\title{
POMBA GIRA Y OTR@S CHIC@S DEL MONTÓN: KIMBANDA QUEER EN BUENOS AIRES ${ }^{1}$
}

\section{Pablo Maximiliano Ojeda ${ }^{2}$}

Resumen: Este artículo analiza las prácticas de un grupo de mujeres trans y hombres gays no binarios, miembros iniciados de un templo afroumbandista del Gran Buenos Aires. En particular, profundiza sobre sus experiencias de expresión sexo-genérica en torno a la kimbanda, línea que experimenta en los últimos años un notable crecimiento en el ámbito local. Mediante observaciones y entrevistas en profundidad, indaga en el vínculo que se establece entre los adeptos y la entidad femenina patrocinante del ritual, Pomba Gira. En este sentido, explora las construcciones identitarias que se cimentan en el transcurrir cotidiano de la vida en el templo legitimadas por aspectos míticos, sociorreligiosos e históricos.

Palabras-clave: Pomba Gira; Kimbanda; Queer; Buenos Aires.

\section{POMBA GIRA AND OTHER GIRLS OF THE HEAP: KIMBANDA QUEER IN} BUENOS AIRES

Abstract: This paper analyzes the practices of a group of trans women and non-binary gay men, initiated members of an Afro-Umbandista temple in Buenos Aires. In particular, delves into her experiences of gender expression around kimbanda, a line that has experienced a remarkable growth in recent years at the local level. Through in-depth observations and interviews, she investigates the link established between the followers and the female sponsor of the ritual, Pomba Gira. Finally,

${ }^{1}$ Como citar: OJEDA, Pablo Maximiliano. Pomba Gira y otr@s chic@s del montón: kimbanda queer en Buenos Aires. Debates do NER, Porto Alegre, ano 21, n. 39, p. 317-341, 2021..

${ }^{2}$ Doutorando em Ciências Sociais pela Universidade Latino-Americana de Ciências Sociais, bolsista do Consejo Nacional de Investigaciones Científicas y Técnicas e pesquisador no Instituto de Investigaciones en Estudios de Género da Facultad de Filosofía y Letras da Universidad de Buenos Aires, Argentina. E-mail: pmojeda@hotmail.com. ORCID: https://orcid.org/0000-0003-3218-4142. 
it identifies that this identity construction is not only based on the daily life of the temple, but is legitimized by mythical, socio-religious and historical aspects.

Keywords: : Pomba Gira; Kimbanda; Queer; Buenos Aires.

\section{INTRODUCCIÓN}

Mi investigación construye su edificio sobre dos ejes empíricos: el fenómeno afro-religioso (la kimbanda) y el universo gay no binario, marica, trans (lo queer), tal como se desarrollan en el escenario de la Argentina actual. Para ello he implementado un estudio etnográfico en una pequeña comunidad que lleva a cabo sus prácticas espirituales en un terreiro ubicado en la zona norte del Gran Buenos Aires, llamado familiarmente por su líder y los fieles La Rosadita. Me he detenido particularmente, en el análisis de uno de los rituales africanistas que allí se realizan, denominado kimbanda, y en el estrecho vínculo que se establece entre la entidad espiritual patrocinante del rito, Pomba Gira, y un grupo de iniciados queer que participan del culto. En este sentido, mi investigación entiende este último término como personas asignadas "varón" al nacer, que atraviesan - o han atravesado - un proceso de construcción de su identidad sexo-genérica, a partir de subjetivaciones vinculadas a lo femenino: transexuales, travestis, drag queens, crossdressers, gays afeminados, etc. El funcionamiento de este templo, activo desde los años ochenta hasta la actualidad, coincide con un período singular de nuestra historia reciente, que representa mucho más que el retorno a las urnas, en el sentido de que adscribe a una nueva forma de ejercicio de la ciudadanía, en construcción desde entonces, que habilita la lucha de las identidades disidentes también mediante la práctica religiosa.

En la Argentina la identidad afro ha sido borrada -relegada folclóricamente a tiempos coloniales -, de la memoria histórica (Geler y Guzmán, 2013; Picotti, 1998). Sin embargo, existe una persistencia de las religiosidades de matriz africana en el acervo social - principalmente en la contracultura 
urbana y suburbana -, no lo suficientemente relevada aún por los estudios académicos. Esto resulta evidente si consideramos el número de templos anotados en el Registro Nacional de Cultos no católicos (Mallimaci, 2013), y en los resultados de indagaciones preliminares que me han conectado con amplias redes de grupos de practicantes en ciudades de todo el país. Veamos, por ejemplo, la siguiente nómina - con total de miembros -, de grupos africanistas argentinos en la red social Facebook: Nación, umbanda y kimbanda: 42.213; A pura religión!!!: 29.923; El reino de las almas: 25.352; Pomba Gira hechizos y rituales: 23.189; Umbanda y Kimbanda: 18.973; Doctrinas de religión afroamericana: 12.037; Los Siete Portales de Tranca Rua y Padilla: 16.079, entre otros ${ }^{3}$. Este relevamiento digital dialoga implícitamente en mi trabajo con la información disponible en los registros oficiales, que resulta insuficiente o incompleta debido a la alta estigmatización que opera sobre estas creencias, y por supuesto, con los datos obtenidos durante el trabajo de campo.

Por otra parte, los rituales afro contienen expresiones performativas que se encuentran en disonancia con los discursos mayoritarios de nuestro país en relación con la corporalidad y la identidad. En este sentido, los avances y aportes más recientes en los estudios sobre disidencias sexo-genéricas (Insausti, 2011, 2015; Simonetto, 2017; Vespucci, 2017), muestran la centralidad de las reconfiguraciones sociales que atravesó el universo queer durante la última dictadura, y extienden el abordaje hacia los años ochenta y noventa. Esos trabajos - centralizados en una mirada pública y política y fundamentalmente en las estrategias de lucha y agencia de las minorías por la ampliación de sus derechos civiles -, resultan de interés para mi investigación, considerando las disidencias de las identidades que abordan, aunque los reinterpreto desde otra perspectiva, ya que privilegio el carácter performático de la construcción del género. Siguiendo a Butler (2007), este ángulo resulta clave para el acercamiento a los cultos africanistas, porque en

${ }^{3}$ Las cifras corresponden a la última consulta realizada (octubre de 2020); y forman parte de un relevamiento de mayor envergadura realizado para mi investigación doctoral. 
ellos los rituales de performatividad revisten -como se verá- una importancia insoslayable. De allí, la singularidad que este trabajo propone, al traer al ruedo un planteo doble, que se pregunta sobre los vínculos entre el género y la religión, observando expresiones minoritarias - y estigmatizadas - de ambos, en el entorno de la historia argentina reciente.

Sabemos que durante la transición democrática comenzó, principalmente en Buenos Aires y otros grandes centros urbanos del país, una reconfiguración y revisibilización de la identidad LGBTI, en coincidencia con una etapa de expansión de la contracultura ${ }^{4}$. Justamente, fue en este contexto cuando muchos templos africanistas que funcionaban activamente en la clandestinidad pasaron a hacerlo en forma pública, sumando nuevos espacios legitimos. En efecto, luego de esta apertura observamos un acelerado crecimiento, un verdadero "boom", al punto que actualmente se hallan inscriptos más de quinientos templos en las principales ciudades del país (Frigerio, 1989, 2001, 2002; Mallimaci, 2013). Es importante notar, que debido al repudio que generan algunas de sus prácticas, como el sacrificio de animales o la adivinación, seguramente existe una subestimación en las estadísticas oficiales. Según han explicado los propios practicantes, el número de espacios destinados a la religión triplican o cuadruplican a los inscriptos oficialmente, lo que está facilitado porque suelen utilizarse domicilios particulares para la práctica.

Dos variantes de la religiosidad de matriz afro predominan en la Argentina: la umbanda, de fuerte carácter sincrético; y el batuque o culto a los orixás, que contiene una mayor cantidad de elementos yoruba preservados. En los templos de Buenos Aires y sus alrededores se suelen practicar ambas corrientes en simultáneo y los adeptos las conciben como distintas etapas de un mismo camino espiritual al que denominan espontáneamente la religión

${ }^{4}$ Estoy pensando en el resurgimiento del rock nacional; las experiencias del teatro under en espacios como el Parakultural; el café Nexor; el taller La Zona de Rafael Bueno; el bar Einstein y la discoteca Cemento de Omar Chabán y Katja Alemann; la Compañía Argentina de Mimo de Ángel Elizondo, la trova rosarina, entre otros.

Debates do NER, Porto Alegre, ANo 2 I, N. 39, P. 3 I 7-34 I, JAN./JUl. 202 I 
(término emic). Si bien se observa aún una mayor presencia de umbanda - la vertiente africanista con mayor representatividad y número de adeptos en el país -, desde hace unos años, una línea menor ha ido cobrando cada vez mayor protagonismo: la kimbanda 5 . Así, para la mayor parte de los fieles, la religión consiste en una práctica conjunta de umbanda, batuque y kimbanda. Es preciso aclarar que en la mayoría de los casos la umbanda actúa como una etapa introductoria en la que el uso de imaginería y elementos provenientes del panteón católico durante las ceremonias, funciona para los principiantes o feligreses, para utilizar un término nativo, como una suerte de conexión facilitadora entre el cristianismo popular - del cual generalmente provienen ,- y los cultos africanistas, - hacia donde se dirigen.

Dentro de este universo de seres en búsqueda de un espacio para su desarrollo espiritual, no es infrecuente encontrar personas con una identidad distinta a lo que dicta la heteronorma. Cualquiera que se acerque por primera vez a un terreiro suburbano del Gran Buenos Aires, tendrá ante sí un fenómeno prácticamente ausente en los espacios dedicados a otras creencias. Observará hombres vestidos de mujer danzando frenéticamente al ritmo de tambores sincopados y si agudiza la percepción, podría llegar a distinguir con sorpresa, que en ocasiones hasta ofician como sacerdotes en los rituales. Es por ello, que mi propuesta consiste en relevar la trayectoria

\footnotetext{
${ }^{5}$ Esta hipótesis forma parte de una discusión muy reciente entre los especialistas argentinos. Mi trabajo de campo desarrollado entre 2014 y 2019 en los terreiros del conurbano bonaerense, me lleva a defender el postulado, ya que tanto los líderes espirituales como los iniciados y practicantes que he entrevistado, sostienen que últimamente la kimbanda ha ganado un mayor espacio; y que las nuevas adquisiciones de fieles que obtienen los templos, generalmente son fruto de la atracción que genera este culto en las clases populares que antes captaba la umbanda, percibida ahora como más anquilosada, tradicional y dificultosa en su acceso. Para mayor información véase el panel "El futuro de las religiones mediúmnicas: antiguas y nuevas maneras de ser múltiple”, FLACSO Argentina, 22 de mayo de 2019. Disertaciones de Alejandro Frigerio y Manuela Rodríguez disponibles en: https://www.youtube.com/watch?v=WvUJ3eYDXUQ\&t=4s y https://www.youtube. $\mathrm{com} /$ watch?v=2TAYAQBsJ9s.
} 
reciente y la cosmovisión de estas religiones afro en el país, conectando el análisis con un abordaje teórico queer, para la comprensión de los procesos de expresión y construcción de identidad, mediante el testimonio directo de los fieles que actualmente practican kimbanda. He construido el texto así, desde una concepción coral, polifónica; Y me gusta pensar que este trabajo contribuye en alguna forma a la revisibilización, revalorización y puesta en escena de un conjunto de voces, sistemáticamente oculto, perseguido, negado u olvidado.

\section{EXÚ Y POMBA GIRA: ¿DEIDADES DISIDENTES?}

Las prácticas religiosas africanistas poseen características propias que las diferencian y distinguen de sus pares en la tradición judeocristiana. Tal vez la más notable de estas desemejanzas se relaciona con la presencia de una pluralidad de cuerpos rituales. Es decir que, durante el ritual, los cuerpos de los practicantes iniciados reciben a diferentes entidades o espíritus que en consonancia con su historia mítica presentan posturas y movimientos corporales que le son propios. En la presente investigación, como afirmé más arriba, me he concentrado específicamente en el estudio de una de estas ceremonias: la kimbanda; cuyas entidades patrocinantes se denominan Exú y Pomba Gira, considerados - en las líneas cultuadas por los templos estudiados - espíritus guía o entidades de baja energía, por ser las más cercanas al hombre y la mujer, y las más terrenales, ya que han tenido varias encarnaciones en las cuales han cometido errores. Generalmente no atravesaron vidas ni muertes apacibles y tranquilas; y siguen reencarnando para liberar su alma y así poder continuar su camino evolutivo. Son por ello astutos y conocen mejor que nadie los miedos y los anhelos que habitan el corazón humano. Les gustan las bebidas alcohólicas, los regalos suntuosos y trabajan áreas difíciles y oscuras de las relaciones interpersonales. Existen distintos tipos de Exús y Pomba Giras. Los Exús más conocidos en el ámbito local son: Exú Rey o Mayoral, Marabó, Mangueira, Lucifer, Tranca Rua, Tirirí, 
Veludo, Dos Ríos, Gira Mundo, Quebra Galho, Pantera Preta, entre otros. Cada uno de ellos trabaja en algo específico, tiene su vestuario, sus gustos y sus ofrendas. También hay infinidad de Pomba Giras: Maria Mulambo, Maria Padilha, Maria Quitéria, Dama da Noite, entre muchas otras que se denominan por los lugares donde moran, como: las Pomba Giras das Almas, das Praias, das Matas, das Encruzilhadas, dos Cruzeiros, da Calunga, da Mafia, do Lixo, do Espacio, y las Ciganas. Cada lugar tiene varias Pomba Giras características, lo que resulta en una cantidad enorme de entidades distintas. Veamos en el siguiente esquema algunas de las características más importantes de estas dos figuras descriptas por los practicantes de kimbanda en los terreiros estudiados: 


\begin{abstract}
Manifestación: Los Exús se manifiestan erguidos, con mucha presencia y desenvoltura, y a veces con un semblante arrogante y algo misterioso. Las Pomba Giras son seductoras y altaneras. Suelen reirse y hablar fuerte, con cierta ironía o severidad y bailan y se desplazan con soltura.

Elementos: Capa, bastón y sombrero. E1 tridente y la calavera. Fuman toscanos los Exús y cigarrillos rubios las Pomba Giras.

Bebida: Exú prefiere whisky, caña y vinos finos o cualquier bebida fuerte. Pomba Gira, sidra, champagne, anis, o licores y vinos dulces.

Color: Para Exú es negro arriba, rojo abajo. Para Pomba Gira es rojo arriba y negro abajo (esto puede variar según la entidad).

Vestimenta: de negro o rojo, pantalón, camisa y trajes para los Exús, y saya (pollera), blusa, vestidos con enaguas, corsé, chales y sombreros para las Pomba Giras.

Día: todos los lunes o los sábados (según la linea y la casa religiosa).

Saludo ritual: Atotó Baba o Laroyé.

Ofrendas: se le ofrecen distintos tipos de carnes, crudas o cocidas en múltiplos de siete. También papas, maiz entero o tostado y pochoclo. Para las Pomba Giras también pueden ser bombones, o masas dulces. Se utiliza miel de abeja y aceite de dendé para los asentamientos. Flores, sobre todo las rosas rojas y los claveles blancos.
\end{abstract}

Lugar de despacho: especialmente en el cementerio y en los cruces de calles y rutas.

Fonte: Pablo Maximiliano Ojeda, 2021.

Los informantes describen a Exú como una entidad capacitada para "transitar por lugares oscuros"; Es decir, esos sitios a los cuales otras entidades, por su luminosidad, no tienen fácil el acceso. Sostienen también que Exú es único, pero a la vez es plural; y tanto es hombre-masculino, como mujer-femenina. Epítome de la dualidad, maneja magistralmente las energías polarizadas del género; y es esa amplia versatilidad la que lo habilita para el engaño, la confusión y el conflicto. En este sentido, se yergue como una totalidad que - si sabe manejarse -, puede resultar beneficiosa para quien 
le rinde culto correctamente tal como indica la doctrina. Por otra parte, se afirma que su cercanía y afinidad con lo humano le confieren un extraordinario poder, que le permite interceder en todo tipo de asuntos terrenales en forma eficaz. Resulta por ello de cuidado, aunque también, en cierto sentido peligroso, ya que posee indistintamente tanto cualidades para el bien como para el mal.

Tres son las instancias rituales necesarias para acceder -como hijo de religión-a los beneficios sagrados que ofrecen los trabajos de Exú y Pomba Gira: 1) el día que se los incorpora por primera vez; 2) el momento en que se realiza su asentamiento; y 3) cuando se los libera. En el segundo de estos pasos, tal vez el de mayor importancia, la fijación del otá - nacimiento de la entidad sobre una piedra sagrada colocada ritualmente en la casa religiosa -, consiste en asentar la tempestuosa y descentrada energía del Exú o la Pomba Gira en cuestión, a fin de educarla y poder así obtener beneficios espirituales de la misma. Sólo a partir de esta interacción evolucionarán ambas energías en forma conjunta: la del hijo y la de la entidad. El siguiente paso en este camino sagrado consiste en realizar las obligaciones rituales correspondientes para la entidad. Durante este tránsito, lo primero que debe hacer el hijo es darle de comer (jantar) a su Exú o Pomba Gira. Esta ofrenda, denominada ebó, implica entregarle a la entidad un conjunto de regalos: bebidas, alimentos y objetos rituales de su agrado, que el hijo debe ofrecer para pedir o para agradecer, según el caso. Para ilustrar este evento, transcribo in extenso una de mis primeras notas de campo, que describe un ebó que presencié en $L a$ Rosadita, el terreiro donde realicé la etnografía:

Son casi las diez de la noche, la ceremonia está por comenzar. Suenan permanentemente desde hace minutos dos tambores (un djembé y un shékere) y dos cinetas (campanillas). En el recinto se encuentra el jefe de la casa y una mae-de-santo de otro terreiro como invitada de honor. La mayoría de los presentes no se halla aun vestido para la ocasión. En breve lucirán pantalón negro, quienes llaman a Exú, polleras largas quienes llaman a Pomba Gira., - según me explica un hijo de la casa que se ha ofrecido para asistirme en la 
observación -. Esto es indistinto del género de la persona, por lo tanto, puede haber mujeres con pantalón y hombres con pollera. Todo el vestuario es negro, blanco y rojo y todos van descalzos.

La primera entidad en llegar es la Pomba Gira de la mae invitada, luego el Exú del jefe de la casa. Los espíritus incorporados se anuncian caminando hacia atrás, de espaldas a la puerta del templo y con la mirada fija en los tambores. Las expresiones de los médiums han cambiado, así como su actitud corporal. Alguien se acerca y les entrega prendas nuevas: sombreros, capas y bastones, que se colocan graciosamente. Luego las entidades son convidadas con un trago y cigarrillos, que beben y fuman respectivamente. Comienzan a saludar a los presentes con distintos tipos de actitudes: se arrodillan, gritan ruidosamente o ríen a carcajadas.

Varios de los presentes comienzan a girar, en sentido opuesto a las agujas del reloj - son los hijos más jóvenes de la casa que están llamando a sus entidades, ahora que los mayores han incorporado pueden hacerlo, me dice mi informante -. La Pomba Gira de la mae invitada - una soberbia Maria Padilha, como sabré después - se acerca y me ofrece una copa (de sidra muy fresca), que acepto sorprendido y halagado antes de unirnos en un elegante brindis. Luego se dirige a una hija de la casa y la reta en portuñol «eu no voy a permitir que dañe a meu filha»; No estoy al tanto de la situación, pero es evidente que ha habido un conflicto interno entre la "retada" y alguien que no está presente y la entidad está interfiriendo en su favor.

Pasado este episodio breve pero incómodo, las entidades bailan un rato largo, todos ríen, beben y fuman. Luego se dirigen a la esfera (lugar donde están asentados los Exús y Pomba Giras de la casa) para sacrificar varios "dos pies" (gallos/gallinas) y un "cuatro pies" (chivo). No se me permite ingresar a esa parte del ritual por no ser un iniciado, pero mi informante me cuenta lo que sucede allí: Exú está por jantar (comer) el axoró (sangre animal), que será vertido sobre el $o t a ́$, la piedra sagrada. La forma de hacerlo es untando el axoró en las manos y los pies del médium, con el fin de "poner en circulación la energía y volverse uno con su hijo».

Cuando esta ceremonia finaliza, los animales son trasladados a la cocina donde se los limpia, y se los freeza. Según mi informante, la carne será utilizada 
luego en otro tipo de evento, porque «nada se desperdicia». Pasada la una de la madrugada, el ebó llega a su fin.

Una de las cosas que más llamó mi atención en el ebó que relato más arriba, no fue tanto el sacrificio de los animales -a los que vi entrar vivos en la esfera y luego ser ingresados en un freezer de tamaño industrial-, sino el lugar de poder jerárquico detentado por las dos figuras más relevantes que se hallaban presentes en la ceremonia esa noche. Me refiero al jefe de la casa (abiertamente homosexual) y la mae-de-santo invitada, una mujer trans de unos cincuenta ańos a quienes - estuviesen incorporados o no -, todos reverenciaban y trataban con suma deferencia y admiración. Esta particularidad me llevó a pensar en la existencia de un entramado peculiar entre el ritual y las identidades sexo-genéricas. Al respecto, Matory (2005; 2006) sostiene que ciertos patrones simbólicos presentes en las religiones del complejo atlántico/yoruba -al que pertenece la kimbanda-, explican la presencia hegemónica de mujeres y homosexuales masculinos en el sacerdocio africanista. Esta situación se hallaría favorecida por una "articulación de conceptos particularmente brasileros con una semiótica de la posesión evidentemente yoruba [en la que] un cierto tipo de homosexualidad se torna ventajoso en el servicio de los dioses" (Matory, 2005, p. 216). Este autor fundamenta su análisis en el uso del verbo gun, palabra yoruba que describe tanto el ingreso de la divinidad en la cabeza del iniciado, como el acto de montar un caballo o un compañero sexual, así como el vínculo sagrado de carácter conyugal que los sacerdotes - sean hombres o mujeres establecen con sus entidades. De allí se desprendería también otro término muy presente entre los fieles africanistas: cavalo, utilizado habitualmente para denominar al médium, es decir, la persona que incorpora en el ritual.

La percepción del género en este caso, debe ser entendida como una estructura de relaciones jerárquica que pone en juego el rol y el lugar social, más que las determinaciones biológicas preexistentes. Ello explicaría la presencia habitual de bichas (término utilizado en Brasil para los hombres gays que se comportan de manera pasiva en la relación sexual) que ofician como 
pais-de-santo, propiciada por esta disposición a ser penetrados o montados, que caracteriza en África a las personas asociadas a la incorporación de los orixás. El hecho de que, en el llamado "paradigma latino-mediterráneo" (Murray, 1995; Guimarães, 2004; Fry, 1982), por mucho tiempo la tradición dividió el comportamiento sexual en categorías jerárquicamente relacionadas con la actividad efectuada durante la relación sexual (activa o pasiva), reafirma la idea de que lo que ocurrió con el desarrollo afroumbandista fue una superposición de conceptos que se sintetizaron en forma hierogámica y ritual, en el simbolismo nupcial de la iniciación y la posesión. Esto habría hecho que tanto las bichas como las mujeres (trans o cis género), fueran depositarias preferenciales del favor y el poder divinos; y por lo tanto más aptas para el desarrollo de la mediumnidad.

En este sentido, la tan mentada dualidad asignada a los Exús evidencia una relación con la dimensión sexo-genérica y posee un origen histórico. Augras (2000) sostiene que hubo un proceso de "pasteurización" del panteón africano al atravesar el Atlántico en épocas de la trata esclavista, que afectó profundamente el concepto de lo femenino en su dimensión sagrada. Según esta autora, se trató de un proceso de "blanqueamiento" propiciado por los umbandistas brasileños de clase media, que en los años treinta buscaban legitimar sus prácticas religiosas y alejarlas de la asociación colectiva que poseían con la negridad africana. Así, aunque las figuras de las orixás femeninas más tradicionales - Iemanjá, Oiá, Oxum - sobrevivieron en los terreiros de umbanda y candomblé, resultaron vaciadas de su contenido sexual y genital, dando lugar al surgimiento de una nueva figura que condensaba estos aspectos presentados ahora con una connotación negativa, pero que aun así otorgaba ciertos permisos de movilidad a las mujeres: Pomba Gira (Augras, 2000, p. 18-20). Una entidad de amplio desarrollo en territorio americano -aunque se cree, no exclusiva de éste (Capone, 1999, p. 109; Carneiro, 2008, p. 71) - que en su representación arquetípica permitió una pervivencia de aspectos asociados a la vida libertina y a una expresión más libre de la sexualidad y el deseo femeninos. De esta construcción sincrética proviene esta figura, aparecida por primera vez en las sesiones umbandistas, 
pero que inmediatamente se sitúa en un área separada. De este modo, aquellos aspectos reprimidos por el africanismo tradicional en su traspaso a América encuentran su lugar de expresión en la creación de una nueva línea, asociada a la izquierda, la polaridad negativa y las prácticas de "magia negra": la kimbanda. Sin embargo, como hemos visto, la energía descentrada y arrolladora de las entidades de la kimbanda pueden ser controladas y utilizadas en favor del iniciado, si se siguen al pie de la letra las normas y pautas rituales indicadas por la doctrina. Estas dinámicas nos permiten comprender la realidad compleja y marginal que adquiere este culto, periférico e insurrecto desde su origen; y el atractivo que representa - como lugar de expresión y de construcción subjetiva - para las identidades sexo-genéricas disidentes, ya que éstas "transitan entre la adhesión a la norma sexual y de género dominante y su transgresión, afirmando, a pesar de todos los conflictos, las vacilaciones y las dificultades de que 'otros mundos' son posibles" (Birman, 2005, p. 412).

\section{LÓGICAS Y PRÁCTICAS RITUALES}

Es preciso aclarar, que pese a las diferencias litúrgicas y cosmovisionales que puedan encontrarse entre las distintas versiones - problema de largo alcance, y cuya complejidad excede los límites de esta comunicación-, ciertas características son compartidas por el universo espiritual africanista: 1) son religiones de posesión, en las cuales distintas entidades espirituales se apoderan y ocupan a los médiums mediante el trance; 2) son religiones de iniciación, es decir, el ingreso a la religión ocurre a través de una serie de rituales que buscan profundizar la integración del sujeto; 3) son religiones mágicas, porque atienden demandas específicas, sobre todo relacionadas con las áreas de salud, económica y sentimental; 4) son religiones emocionales que envuelven al individuo como un todo, en el cual el cuerpo ocupa un lugar destacado; 5) son religiones universales porque están abiertas a todos los individuos sin distinción de procedencia; y 6) son religiones trasnacionales en 
las cuales se involucran individuos de distintos países (Oro, 2008, p. 12-13). La práctica del trance mediúmnico, así como la especificidad ritual que el fiel va desarrollando y adquiriendo con el tiempo, propicia un vínculo particular con las entidades en el contexto de la casa religiosa, ya que cada uno de estos espacios posee secretos y singularidades propias. No obstante, existen al menos tres niveles o grados, que los practicantes entrevistados identifican y que involucran diferentes niveles de conciencia en el proceso de su educación religiosa: 1) la irradiación (cosquilleo corporal que anuncia la cercana presencia de una entidad); 2) el encostamiento (entrada y salida de las entidades aún no afianzadas); y 3) la incorporación propiamente dicha. Las entidades espirituales africanistas se manifiestan en la materia (el cuerpo vivo de una persona) con el fin de evolucionar, efectuando trabajos caritativos para otorgar el axé. Este último concepto, representa la energía dinámica o la fuerza sagrada que, según los africanistas, puede ser dada o recibida y sobre la que gira todo el sentido que adquiere el culto ya que, mediante este intercambio, el religioso afirma que crece y desarrolla las cualidades positivas que lo convierten paulatinamente, con el tiempo y la práctica, en un ser completo y mejor.

$\mathrm{El}$ ingreso a la práctica religiosa se da por adoctrinamiento; Si alguien tiene o no buena doctrina es algo que se escucha a menudo en los terreiros, sobre todo para dar cuenta de la actuación de las entidades durante las sesiones. Esta es la tecnología más específica que se desarrolla en el marco del aprendizaje de la mediumnidad por parte del adepto. Si una entidad espiritual no se comporta como es debido, se entiende que el responsable es el hijo, el fiel, que no ha interiorizado correctamente aún las formas y los contenidos del culto. Por eso es que se afirma que a la entidad hay que darle desarrollo; es decir, ir de a poco enseñándole lo que debe hacer y cómo debe comportarse. En este sentido, se trata de un aprendizaje conjunto, que involucra al fiel y a la entidad, porque ambos se desarrollan juntos. El hijo también va conociendo a su entidad paulatinamente a medida que ella le va contando quién es, cómo y dónde vivió, cuándo y por qué murió, etc. Ese proceso de adoctrinamiento mutuo es acompañado y supervisado por 
el pai o la mae-de-santo, ya que es necesario vigilar que no sucedan cosas imprevistas durante las ceremonias. Cuando algo sale mal, se entiende que es falta de aprendizaje o de algún incumplimiento ritual, y jamás es responsabilidad de la entidad. Además de un mutuo reconocimiento, hay un cuidado conjunto: las entidades necesitan que su hijo esté sano, por eso es preciso cuidarlo ya que es en su materia donde ellos pueden hacerse presente (Rodríguez, 2016). De la misma manera, el hijo debe cuidar de su entidad, darle las ofrendas necesarias, alimentarla y no descuidar su asentamiento, es decir, el espacio sagrado donde la entidad habita luego de la iniciación.

Todo este protocolo se aprende en las llamadas fiestas o sesiones, y sobre todo camboneando - término emic que proviene de cambón [ayudante] y designa la acción de asistir a un médium durante el proceso ritual de incorporación -, que es donde se va diferenciando lo que le gusta y lo que usa cada entidad; también ayudando en las tareas cotidianas de mantenimiento de la casa religiosa, en las conversaciones pasajeras y en momentos precisos de enseñanza de la doctrina por parte de los líderes religiosos o iniciados más experimentados. Es decir, se trata de un esfuerzo para ambos: para la entidad que debe aprender a estar en ese cuerpo, a desenvolverse como corresponde, si quiere evolucionar; y para el fiel, que debe atender y responder a las demandas si desea el favor y el axé de esa entidad. Es una relación que implica una agencia conjunta, un esfuerzo y un cuidado mutuo y requiere de mucho tiempo y preparación. Existen en primer término las sesiones denominadas de desarrollo: son aquellas destinadas especialmente a asentar a la entidad en el médium. Esto se hace mediante la gira, en la cual todos se focalizan en el movimiento de uno para ayudarlo y sostenerlo en el trance, con el fin de que logre pasar del encostamiento a la incorporación. Estas giras pueden durar hasta media hora. Varias veces presencié eventos de este tipo, algunos de los cuales terminaban en incorporación y otros no. Otra forma de asentar es dejar al adepto incorporado mucho tiempo, no darle salida a la entidad, para que ésta vaya acostumbrándose a estar en el cuerpo del fiel, a estar encarnada. 
Esta es la forma como el adoctrinamiento se hace posible; en principio, sobre la expectativa de que el trance mediúmnico acontezca. Para que ello suceda es necesario que el fiel participe de las ceremonias, primero camboneando y luego propiciando el trance. Una vez que la incorporación ocurre ésta debe desarrollarse, afianzarse; y ambos - fiel y entidad espiritual - deben reconocerse, cuidarse y entenderse. Este proceso lleva tiempo y está calificado como "arduo" por parte de los fieles. Es un camino de aprendizaje que involucra nuevos sentidos, experiencias corporales y códigos de socialización; así como nuevos vínculos con esos otros materiales e inmateriales que habitan el espacio ritual.

\section{UN TERREIRO PROPIO}

Más allá de la línea a la que pertenezca la casa en cuestión -que como he afirmado, muchas veces se basan en secretos y doctrinas exclusivas-, existe una suerte de estructura que unifica por sobre la multiplicidad. Una de estas características generalizadoras es que el sistema posee una idea equivalente a la del bien, pero no a la del pecado, como ocurre en la dualidad que presentan las religiones del campo cristiano. De modo tal, que aquellas personas que por su sexualidad disidente son discriminadas e infravaloradas en otros ámbitos religiosos, encuentran en el africanismo un espacio de contención y revalorización que les permite expresar su identidad sexo-genérica sin censura (Birman, 1995, 2005; Fry, 1977, 1982). Es este precisamente uno de los puntos en el cual me ha interesado detenerme, es decir, esta performatividad específica de la kimbanda, que representa una experiencia espiritual de transformación durante el ritual y que posee contactos inequívocos con la expresión de género en la construcción de las identidades LGBTI. Si aceptamos, como afirma Teresa de Lauretis (1989, p. 9), que el género "es un efecto compuesto de representaciones discursivas y visuales" que emanan de varias instituciones tal y como son propuestas y resignificadas desde la estructura del moderno estado nación; vale decir, la 
familia, el sistema educacional, los medios de comunicación, la medicina, el derecho, y por supuesto la religión, tal vez podamos adentrarnos más profundamente en la cuestión propuesta, ya que la representación y la construcción del género constituyen siempre una forma de negociación con el poder y cuanto menos inteligible sea aquél, más expuesto a la violencia, y en condición más vulnerable se hallará (Butler, 2007).

La construcción de la identidad en lo que atañe al género es entonces, tanto producto como representación, una representación que tiene efectos reales en la vida material de los individuos. De Lauretis (1989) sostiene que esa representación se realiza cuando se convierte en una auto representación, es decir en una forma particular de percepción de la propia identidad social y subjetiva; el género sería entonces, tanto una atribución como una apropiación. Y el terreiro, la communitas (Turner, 1988) de la kimbanda, un espacio en el cual expresarlo libremente fuera de los prejuicios, las ataduras o las limitaciones que existirían fuera de él, basándose en la justificación o legitimación que se obtiene desde la cosmovisión y la práctica socio-ritual del culto. La kimbanda constituiría en este sentido, una instancia performativa liberadora o bien, como ha afirmado oportunamente una de las informantes: "un espacio donde poder ser lo que se es".

Yo siempre me sentí diferente. Ya desde chiquitito, cuando todavía era varón, jugaba con las muñecas y la cocinita de juguete de mi hermana. Nunca me gustaron el fútbol, los soldaditos ni la lucha... nada de lo que hacían los otros chicos. Antes de entrar en religión, hace muchos años de esto, vivía sintiéndome mal por mi diferencia... y hasta pensaba que era enferma o que algo estaba mal en mí. Pero cuando arranqué mis primeras kimbandas empecé a sentirme mejor... como más libre... y de a poco me fui sintiendo más tranquila. Después, cuando me jogaron buzios [oráculo que determina el orixá regente], y supe que mi guía de cabeza es 'un ella', entendí que nunca estuve enferma, solamente soy distinta y eso no está mal, al contrario, soy feliz porque soy ella. (Tina, seudónimo, comunicación personal). 
Dejando de lado u opacando si se quiere, otras dimensiones de la identidad personal o social presentes en la práctica religiosa, he privilegiado para definir a mis informantes LGBTI que asisten a La Rosadita, la utilización, más indicada y abarcativa del concepto queer que, aunque conserva algo de su connotación histórica que lo ha relacionado con la "desviación sexual", es el que mejor expresa un tipo de mirada que observa un espectro más amplio con respecto a la cuestión que nos ocupa, tal vez porque es el que más lejano se encuentra de lo que es específico de la orientación sexual, a la vez que engloba a todo aquello que se halla por fuera de la heteronorma. Es interesante mencionar al respecto, que el vocablo conlleva en sí mismo una acepción binaria que le confiere a la vez fuerza y sentido, me refiero a que en gran medida debe su existencia y significado a su opuesto straight, palabra que traducida a nuestro idioma podría interpretarse como derecho, recto, heterosexual (Butler, 2007; Laqueur, 1994; Llamas, 1998). Lo queer entonces, nos hablaría de una esencia subversiva y transgresora de aquello, es decir que expresaría una sensibilidad contraria a la tipología dominante que trasciende las fronteras de la actividad o identidad específicamente sexual del individuo (Guasch, 1998), y es por ello que encaja tan bien como concepto en pos de una mejor comprensión teórica de mi trabajo.

Numerosos testimonios en línea con las palabras de Tina, he registrado en las profundas entrevistas que realicé durante estos años en mi trabajo de campo. A partir de ellos, todo indica que es en la cuestión identitaria en relación al género donde estaría puesto el acento. Y lo que se resuelve, en parte, en ese sentido de pertenencia de los adeptos para con su comunidad espiritual. Un ámbito que les permite conectar de manera directa a través de la performatividad ritual con un aspecto puntual de su identidad sexo-genérica. En este sentido, ha constituido una constante en los relatos, la fascinación del primer contacto, el primer acercamiento a Pomba Gira. Es decir, las primeras sesiones a la que concurrieron como feligreses, consultantes o depositarios de ayuda espiritual, cuando atravesaban la fase inicial en las etapas de contacto con la religión. 
Cuando la vi por primera vez [habla de una Pomba Gira incorporada en otro adepto] experimenté una sensación de explosión interna y de tranquilidad a la vez.

¿Cómo fue exactamente? ¿Podrías ampliar?

Es difícil de explicar... voy a intentar... Tranquilidad porque entendí que no era lo que yo hacía sino lo que era, eso me dio paz. Y una explosión interna porque fue muy fuerte, por eso digo una explosión, algo muy inmenso, que ya no se puede esconder.

¿Querias ser Pomba Gira?

No lo tuve tan claro en un principio... pero sí, algo así.

¿Y quién es Pomba Gira?

Mi señora... [piensa] ...pero antes fue una mujer, una mujer preciosa, segura, sin miedo.

¿Y vos, vos quién sos?

¿Ahora decís? Yo creo que gracias a la religión soy una persona más feliz... cómo explicarte, más... más... completa... más de verdad que antes.

(Ángel, seudónimo, comunicación personal)

Decidí transcribir este fragmento de la entrevista en forma textual porque considero que es representativo, tal vez como ningún otro, del bienestar revelador experimentado ante un primer contacto in situ con la entidad femenina patrocinante del ritual; y el deseo, -posteriormente alcanzado en todos los casos -, de protagonizarlo.

Yo quiero ser aceptada en forma total, más allá de lo que soy o eso que los demás creen que soy, por cómo se me ve o porque vengo acá [se refiere al templo]. O sea, vos ahora estás charlando conmigo y te debo parecer 'un trava medio ridículo', pero en un rato me vas a ver convertida en una diosa porque yo tengo mucha Pomba Gira. Y lo mismo mañana a la mañana voy a tomar mate a lo de mi familia en joggineta y todo el pelo adentro de la gorra, pero voy a seguir siendo yo. No entiendo que es lo que haría la diferencia, si ahí siempre estoy yo. (Apola, seudónimo, comunicación personal) 
A partir de la definición y el fortalecimiento del vínculo entre el adepto y su Pomba Gira, el practicante adquiere y/o refuerza ciertas características y atributos propios de la personalidad de la entidad. Desde entonces, el comportamiento del iniciado cobra un nuevo significado al conectar y coincidir con el de su espíritu-guía; y es en este sentido, que la identidad del fiel queer es reinterpretada sin conflicto alguno con su sexo asignado al nacer, a la vez que resulta integrada al ámbito social de su terreiro y legitimada desde el aspecto mítico.

Me gusta que me hagas todas estas preguntas sobre mí, mis compañeras y mi religión, creo que esto puede ayudar a que la gente deje de vernos como bichos raros. Somos chicas distintas nosotras, especiales, y espero que esto pueda servir para que se entienda que yo no soy ningún monstruo, que solo trato de vivir mi vida de la mejor manera posible ayudando a los demás en todo lo que pueda, incluso a aquellos que me discriminan por mi condición y mis creencias. (La Madonnita, seudónimo, comunicación personal)

Obsérvese así, la interesante comunión entre lo afro y lo queer presente en los testimonios recogidos; y en los rituales kimbanda que he tenido la posibilidad de presenciar numerosas veces en La Rosadita. Allí, los practicantes establecen una conexión privilegiada con una identidad interior que se expresa durante las prácticas rituales colectivas luego de la incorporación de la entidad patrocinante. Por otra parte, son más que conscientes de la marginalidad que rodea tanto su identidad personal como la religiosa, ya que son concebidos por el resto de la sociedad como "locos", "desviados", "macumberos" o "raros". Resulta muy notable aquí la conexión con el concepto queer, así como la apropiación de esta identidad social y espiritual como bandera identitaria ante una sociedad como la argentina, resistente aún a muchas expresiones de la diversidad. 


\section{BREVE REFLEXIÓN FINAL}

La kimbanda que se practica en la actualidad en la ciudad de Buenos Aires y alrededores actúa como un espacio que contiene lo marginal, lo andrógino, lo diferente y lo subversivo, en relación con la estructura de valores dominantes y muy presentes aun en la sociedad patriarcal, cristiana y heteronormada. Dentro de este marco, constituye un ámbito propicio para la participación de personas que, por su identidad o sexualidad disidente con respecto a estos esquemas tradicionales, resultan discriminadas o estigmatizadas en otros espacios religiosos mayoritarios. Siguiendo esta línea, resulta pertinente destacar que el culto facilita la escisión del binomio sexo/género y que ello se materializa en el espacio ritual. Lo que otorga al fiel la posibilidad de representar los géneros (masculino o femenino), en forma independiente del sexo asignado al nacer. De esta manera, la posibilidad de romper con la unilateralidad es aceptada, contenida y legitimada por los aspectos cosmogónicos, sociales e históricos de la religión. Así lo demuestran las voces de l@s chic@s que han hablado en este artículo, quienes atravesaron una serie de lugares comunes a toda autobiografía marica (o gay, o trans): El descubrimiento temprano de la diferencia, la exclusión del universo hegemónico heteronormativo, la imposibilidad de vivir la propia vida por la vigilancia familiar o institucional, y finalmente, la búsqueda y el arribo a un nuevo horizonte.

Lo distinto, lo trans, lo disidente producen invariablemente un efecto magnético, que se relaciona tal vez con otras figuras que habitan nuestro imaginario social. Constituyéndose, así, como lo salvaje o lo monstruoso, por la inquietud que su sola presencia genera y por la eliminación evidente de los límites, aquellos en donde lo imposible puede volverse realidad. Esta suerte de retorno simbólico, de re-ligación, que tan bien se expresa en el propio sentido semántico de las creencias y la espiritualidad. Esta explosión inmensa, como afirma Ángel en su relato, que ya no puede ni quiere esconderse, porque se vuelve real nada menos que a través del cuerpo. Y se erige en pos de la equidad, la visibilidad, la pluralidad y el derecho inenajenable a 
la construcción de la propia identidad, contenida por otro derecho tanto o más inequívoco que aquel: el derecho a la fe, a elegir libremente en qué creer.

Habitamos un mundo dispar, complejo, dinámico, en el que la pluralidad de opciones y la suma de individualidades constituyen un amplio abanico de posibilidades. En él, un culto de matriz afrobrasileńa, resignificado y reestructurado en el campo religioso local como la kimbanda, aloja expresiones de la diversidad generando nuevos ámbitos para el desarrollo de la espiritualidad. Y el universo queer, que ha comprendido bien el guiño, no es ajeno, y hacia allí va en su búsqueda de nuevos espacios y conquistas donde poder ser. En este marco, emergen sitios como La Rosadita, que claramente no abundan - y por ello es necesario relevarlos -, en una sociedad que está cambiando lentamente, tal como lo demuestran los innegables avances en materia de derechos civiles, pero que aún se encuentra temerosa y resistente a lo distinto y por ello no siempre se muestra amigable.

\section{REFERENCIAS}

AUGRAS, Monique. De Iyá a Mi Pomba Gira: Transformacoes e Símbolos da Libido. In: MARCONDES DE MOURA, C. S. Candomblé: Religiao do Corpo e da Alma. Río de Janeiro: Pallas, 2000 [1987].

BIRMAN, Patricia. Transas e trances: sexo e gênero nos cultos afro-brasileiros, um sobrevôo. Revista de Estudios Feministas, N 13 (2), p. 403-414, 2005.

BIRMAN, Patricia. Fazer estilo criando gênero. Río de Janeiro: Relume Dumará, 1995.

BUTLER, Judith. El género en disputa. El feminismo y la subversión de la identidad. Buenos Aires: Paidós, 2007.

BUTLER, Judith. Cuerpos que importan: Sobre los limites materiales y discursivos del "sexo". Buenos Aires: Paidós, 2002.

CAPONE, Stefania. La quête de l'Afrique dans le candomblé: pouvoir et tradition au Brésil. París: Karthala, 1999. 
CARNEIRO, Edison. Candomblés da Bahia. São Paulo: Editora Martins Fontes, 2008.

DE LAURETIS, Teresa. Technologies of Gender: Essays on Theory. Londres: Macmillan Press, p. 1-30, 1989.

FRIGERIO, Alejandro. La umbanda no es una religión de ignorantes y mediocres: estrategias frente la estigmatización de las religiones afrobrasileñas en Buenos Aires. Revista de Antropología, No 10, p. 22-33, 1989.

FRIGERIO, Alejandro. Cómo los porteños conocieron a los Orixás. In: PICOTTI, Dina. (ed) El negro en Argentina: Presencia y negación. Buenos Aires: Editores de América Latina, p. 301-331, 2001.

FRIGERIO, Alejandro. La expansión de religiones afrobrasileñas en Argentina: Representaciones conflictivas de cultura, raza y nación en un contexto de integración regional. Archives des Sciences Sociales des Religions. École des Hautes Études en Sciences Sociales, París, No 117, p. 127-150, 2002.

FRY, Peter. Da Hierarquia à Igualdade: A Construção Histórica da Homossexualidade no Brasil. In: Identidade e Política na Cultura Brasileira. Rio de Janeiro, Zahar, p. 87-115, 1982.

FRY, Peter. Mediunidade e sexualidade. Religiáo \& Sociedade, No 1, p. 105-123, 1977.

GELER, Lea; GUZMÁN Florencia (eds.). Cartografías afrolatinoamericanas: perspectivas situadas para análisis transfronterizos. Buenos Aires: Biblos, 2013.

GUASCH, Oscar. La crisis de la heterosexualidad. Barcelona: Leartes, 1998. GUIMARÁES, Carmen Dora. O homossexual visto por entendidos. Río de Janeiro: Garamond, 2004.

INSAUSTI, Santiago Joaquín. Selva, plumas y desconche: Un análisis de las performances masculinas de la femenidad entre las locas del Tigre durante la década del ochenta. Revista Latinoamericana sobre Cuerpos, Emociones y Sociedad. Universidad Nacional de Córdoba. Vol.7, Año 3, 2011. 
INSAUSTI, Santiago Joaquín. Los cuatrocientos homosexuales desaparecidos: memorias de la represión estatal en las sexualidades disidentes en Argentina. In: D'ANTONIO, Débora (comp.). Deseo y represión: sexualidad, género y Estado en la historia reciente argentina. Buenos Aires: Imago Mundi, pp. 63-82, 2015.

LAQUEUR, Thomas. La construcción del sexo: cuerpo y género desde los griegos hasta Freud. Madrid: Crítica, 1994.

LLAMAS MUÑOZ, Ricardo. Teoría torcida: prejuicios y discursos en torno a la "homosexualidad". Madrid, Siglo XXI, 1998.

MALIMACCI, Fortunato. Atlas de las creencias religiosas en la Argentina, Buenos Aires: Biblos, 2013.

MATORY, J. Lorand. Religión Afro-Atlántica: Tradición, Trasnacionalismo y Matriarcado en el Candomblé Brasileño. Editorial Oriente/Casa del Caribe, 2006.

MATORY, J. Lorand. Sex and the Empire That Is No More: Gender and the Politics of Metaphor in Oyo-Yoruba Religion. Nueva York: Berghahn Books, 2005 [1994].

MURRAY, Stephen. Latin American Male Homosexualities. Albuquerque, University of New Mexico Press, 1995.

ORO, Ari. As religiōes afro-brasileiras do Rio Grande do Sul. Debates do NER, Porto Alegre, Ano 9, n. 13, p. 9-23, 2008.

PICOTTI, Dina. La presencia africana en nuestra identidad. Buenos Aires: Ediciones del Sol, 1998.

RODRÍGUEZ, Manuela. Giros de una Mae de Santo. Corporalidad y performatividad en un caso de conversión a las religiones afrobrasileñas en Argentina. (Tesis Doctoral), Reservorio Facultad de Filosofía y Letras, Universidad de Buenos Aires, 2016. 
SEGATO, Rita. La crítica de la colonialidad en ocho ensayos: y una antropologia por demanda. Buenos Aires: Prometeo, 2015.

SEGATO, Rita. Las estructuras elementales de la violencia. Buenos Aires: Prometeo, 2010, pp. 179-246.

SEGATO, Rita. La Nación y sus Otros: raza, etnicidad y diversidad religiosa en tiempos de políticas de la identidad. Buenos Aires: Prometeo, 2007.

SIMONETTO, Patricio. Entre la lujuria y la revolución: el Frente de Liberación Homosexual Argentina. 1967-1976. Universidad Nacional de Quilmes: LibroDigital, 2017.

TURNER, Victor. El proceso ritual: estructura y antiestructura. Madrid: Taurus, 1988.

VESPUCCI, Guido. Homosexualidad, familia y reivindicaciones: de la liberación sexual al matrimonio igualitario. Buenos Aires: UNSAM Edita, 2017.

Recebido em: 19/02/2021

Aprovado em: 30/03/2021 
